Abstracta Iranica

Revue bibliographique pour le domaine irano-aryen

Volume 32-33 | 2013

Comptes rendus des publications de 2009-2010

\title{
L'Iran, derrière le miroir. Coordonné par Christian Bromberger
}

\section{Yoko Suzuki}

\section{(2) OpenEdition}

1 Journals

\section{Édition électronique}

URL : http://journals.openedition.org/abstractairanica/41050

DOI : 10.4000/abstractairanica.41050

ISSN : 1961-960X

Éditeur :

CNRS (UMR 7528 Mondes iraniens et indiens), Éditions de l'IFRI

\section{Édition imprimée}

Date de publication : 1 décembre 2013

ISSN : 0240-8910

Référence électronique

Yoko Suzuki, «L'Iran, derrière le miroir. Coordonné par Christian Bromberger », Abstracta Iranica [En ligne], Volume 32-33 | 2013, document 460, mis en ligne le 01 juillet 2016, consulté le 26 septembre 2020. URL : http://journals.openedition.org/abstractairanica/41050 ; DOI : https://doi.org/10.4000/ abstractairanica.41050

Ce document a été généré automatiquement le 26 septembre 2020.

Tous droits réservés 


\title{
L'Iran, derrière le miroir. Coordonné par Christian Bromberger
}

\author{
Yoko Suzuki
}

\section{RÉFÉRENCE}

L'Iran, derrière le miroir. Coordonné par Christian Bromberger. 2009, 241 p. (Actes sud, La pensée de midi, $n^{\circ} 27$ )

Dans les 153 premières pages de cet ouvrage, 17 chercheurs contribuent à montrer la complexité de la vie et des avis d'Iraniens, représentée par l'expression de "deux images opposées (du pays) » (C. Bromberger) ou celle de « les paradoxes persans » (J.-F. Colosimo). Elle est examinée à travers la biographie d'un ou deux personnages (féministes, sociaux, artistes, sportifs, religieux, politiques, littéraires) pour 15 des auteurs de l'ouvrage, et par la présentation d'une profession, chauffeur de taxi, et d'une discipline, l'archéologie pour le reste.

2 Tous les articles sont très bien édités et rendent la lecture facile. Il faut noter le travail concis et argumenté d'A. Mousavi et N. Nasiri-Moghaddam sur l'archéologie en Iran dont la naissance et le statut ont été non seulement liés aux intérêts scientifiques mais aussi aux politiques domestiques et des pays étrangers qui voulaient fouiller. En outre, deux articles développent remarquablement la biographie comme une arme de recherche socio-anthropologique en faisant la comparaison précise de deux éléments différents. Le premier est celui collectif de M. Saïdi-Shahrouz et P. Ghassemi qui comparent deux personnes connues dans un quartier au sud de Téhéran pour leurs activités sociales, dont le comportement religieux et les tendances politiques sont en contraste, malgré leur objectif similaire. Le deuxième est l'article M. Vatani qui présente une personne ayant "réussi» dans la société iranienne, grâce à son adaptation aux deux régimes, à savoir une transition "logique» d'une attitude favorable au shah à une autre posture, favorable au régime islamique.

Thierry Fabre, Editorial : « Un rêve méditerranéen... » ; 
Christian Bromberger, Introduction : « Paradoxes iraniens »;

Jean-François Colosimo, « Deux dames de Téhéran »;

Masserat Amir-Ebrahimi, « Mme Gohari, la dame des quartiers sud de Téhéran »;

Mina Saïdi-Shahrouz et Parvine Ghassemi, « Les nouveaux pahlavan de Téhéran »;

Mohiaddin Vatani, « Un opportuniste à Ispahan »;

Agnès Devictor, « Shahid Morteza Avini, Cinéaste et martyr ";

Liliane Anjo, « Amir Reza Koohestani : Une figure théâtrale de passeur »;

Alice Bombardier, « Peinture et cinéma, une famille d'artistes à Téhéran » ;

Ariane Zevaco, «A la recherche de la nouvelle voie: un musicien traditionnel et contemporain en Iran »;

Eric Boutroy, « Les Sisyphes de Téhéran »;

Stéphane A. Dudoignon, «Un Mawlawi contre les Pasdaran? »;

Gilles Riaux, « De l'islamisme au séparatisme : la carrière militante de Chehregani »;

Yann Richard, « Un théologien chiite, Mojtahed Shabestari »;

Bernard Hourcade, «Reza, Ancien général des gardiens de la révolution »;

Jean-Pierre Digard, « Une grande figure tribale : A Ja'far-Qoli Rostami Bakhtiyâri » ;

Ali Mousavi et Nader Nasiri-Moghaddam, «Les hauts et les bas de l'archéologie en Iran $»$;

Azita Hempartian, « Châmlou, enfant du siècle ».

\section{AUTEURS}

\section{YOKO SUZUKI}

Paris 